MATEC Web of Conferences 44, 01008 (2016)

DOI: $10.1051 /$ matecconf $/ 20164401008$

C Owned by the authors, published by EDP Sciences, 2016

\title{
The Analysis of the Refined Financial Management of Modern Enterprises
}

\author{
Ran Li \\ ${ }^{1}$ Ran Li, a teacher with a lectureship in Langfang Polytechnic Institute, Hebei Province, China
}

\begin{abstract}
This paper briefly introduces the concept of the refined financial management, elaborates on its characteristics and puts forward some main points about it. It also comes up with some personal suggestions for reference on effective ways of refining financial management.
\end{abstract}

\section{The concept of the refined financial management}

The refined financial management means that the responsibilities for financial management should be fully fulfilled by refining the management responsibilities to make them specific and clear. It requires relevant people must fulfill their duties to complete their work in the shortest time and to check it seriously. Once they find problems, they have to immediately take corresponding measures to make it right. The specific concept of the refined financial management include the following three aspects: Firstly, comprehensive management should be emphasized. The refined financial management requires enterprises to achieve an overall refinement. Secondly, the refined financial management requires enterprises to realize all-personnel management to finish their financial work together, which will achieve the working efficiency and optimal quality of the financial management. Thirdly, the refined financial management attaches importance to the management of the process. Financial management should fully reflect the characteristics of refinement, and follow-up management should strictly control the details in order to improve them.

\section{The characteristics of the refined financial management}

Firstly, the enterprise's refined financial management must make significant changes in all aspects to fully reflect the value of the enterprise's economic activities. Its primary goal is to improve the financial management. It will change the implementation of the financial management, including financial functions, financial work and the transformation of the financial working style. In order to realize the refined financial management, enterprises have to adopt the operating and management mode, and control their financial activities in the entire process. Besides, they should change the nature of their work to achieve its service functions.

Secondly, the refined financial management requires to refine financial management to expand its field. Financial management and work quality can be greatly improved by refining and integrating financial management. To expand the field of financial management is good for the implementation of the "huge financial" strategy inside the enterprise. The procedures of the financial management should be constantly standardized and financial management has to be used for production management. Each department should actively cooperate with one another to complete the enterprise's financial management which makes the enterprise's management more flexible and makes it complete its work effectively.

Thirdly, the realization of the refined financial management of modern enterprise should depend on scientific management means and strict management system. Job responsibilities and internal management system have been continuously improved by establishing work norms and supervision mechanism, which realizes a change from the rule of man to the rule of law and guarantees the fairness and objectivity of the financial management.

Fourthly, the goal of the refined financial management should be to improve the efficiency of enterprises. Its implementation needs to further expand the working field in order to realize the potential value of production and operating activities. The high added value of financial activities can be achieved which can increase economic benefits of the enterprises to the utmost. 


\section{The practical significance of the refined financial management}

With the increasingly fierce market competition, modern enterprises have to realize the refinement of financial management in order to adapt to the development of the times. The implementation of the refined financial management can improve its financial management level, which has a very positive impact on the overall development of enterprises. From the perspective of the enterprise, its management should focus on the refined financial management which requires the enterprise not only expands its operating management, but also strengthens the enterprise's internal financial management. It should have dynamic control and management of the enterprise's finance and realize the transformation of the financial management mode. The enterprise should transform its post-accounting to prebudget, during-the-process control and post-supervision and further constructs its refined financial management system in order to realize centralized management, to further standardize financial accounting procedures, to improve the scientificity and reasonability of the internal control system, and to comprehensively improve the financial analysis system. The implementation of the refined financial management can have a dynamic control over the financial management and make costs get optimal precontrol which enhances the core competitiveness of enterprises.

\section{Main contents of the enterprise's refined financial management}

\subsection{To reinforce the construction of the enterprise's internal control system}

With the continuous development of social economy and the increasingly fierce market competition, modern enterprises are confronted with more and more risks in their operating and management, which has had a great impact on their development. In order to realize an effective control of the enterprise's financial risk, it is necessary for the enterprise to establish a scientific and reasonable internal control system. The refined financial management enables to establish the internal control system which will improve the enterprise's risk control level. However, it is necessary to emphasize that the enterprise's refined financial management may have a negative impact on the establishment of the internal control system. Therefore, the enterprise's internal control system must take this problem into consideration and take positive measures to avoid financial risks.

\subsection{To reinforce the construction of informatization}

The enterprise's refined financial management makes higher requirements for the efficiency of the financial management, and details should be controlled. To reinforce the construction of informatization is good for the realization of the refined financial management. The construction of financial informatization requires to improve both hardware facilities and software. On the one hand, enterprises have to define the scientificity of the informatization content, including decision-making, business and resources and so on. They should also sort out the procedures of informatization construction, specify information analysis, collection and transmission path, etc. On the other hand, enterprises should pay attention to the financial personnel construction. Personnel who have participated in the construction of the informatization system must enhance their training to better improve their comprehensive ability.

\subsection{To promote a comprehensive budget management}

The realization of the enterprise's management goal requires to improve and promote the construction of a comprehensive budget management mode, which can make the enterprise proactive and realize an effective control of costs. The comprehensive budget management includes the budget management of the asset income and the budget management of the assets investment expenditure. Enterprises need to make a detailed analysis of their planning and assets investment income of the previous year when carrying out investment system budget. They should also assess the achievement of investment projects and market. The assets share and expenditure of the incremental assets can be determined. Stock assets can be adjusted. Adjusting the scale and direction guarantees the enterprise's operation and production. The effective implementation of the enterprise's financial management is based on the scientific assets budget. A specific revenue target must be formulated and then refined. Relevant tasks and responsibilities fall on specific departments and individuals, which will increase the possibility of achieving the enterprise's target.

\subsection{To reinforce the construction of the activity- based management system for the refined costs}

Compared with the traditional cost accounting method, the activity-based costing method has its advantages-it can be used to accurately share mutual cost by tracking and looking for motives. Enterprises should implement activity-based costing method and carry out research on their process activities, costs items, services and products. 
They should also provide scientific and reasonable criteria for the design of the cost model. The enterprise's activity-based costing method makes it possible to achieve cost sharing. In order to make an effective analysis of the enterprise's activities, it is necessary to determine the center of their costs. The establishment of the cost center should consider the enterprise's sectors actual conditions. Some sectors have a direct connection with the products. Their possession of resources and costs have to be calculated. Under normal circumstances, primary-level sectors don't produce excessive costs. They should adhere to the principle of efficiency and avoid separating cost center which can't be separated into more than three ones. The activity-based sharing should choose major tasks to participate regularly in the activities; and some minor tasks can be ignored.

\section{Effective methods for the implementation of the enterprise's refined financial management}

\subsection{To strengthen the construction of the financial management personnel}

The financial management personnel are the principal force to carry out financial management. Their comprehensive ability directly determines the efficiency and quality of financial management. Therefore, enterprises must strengthen their internal team construction and improve the overall comprehensive ability of the financial management personnel in order to achieve sustainable development and improve their core market competitiveness. The enterprise should speed up the construction of financial team and improve the quality of personnel according to its financial conditions. The primary task for the enterprise is to cultivate the professional ethics of financial management staff. It should enhance their sense of responsibility and risk awareness and improve their professional responsibility which will be helpful for effectively implementing the enterprise's measures and policies. The enterprise should also improve the enthusiasm of the staff and continuously improve their service awareness. Besides, the enterprise should strengthen the construction of its working style for financial management and correct the working attitude of the financial management personnel. It should cultivate a cautious and careful working style in order to improve the working efficiency and quality. In addition, it should also strengthen the construction of the responsibility system and specify the financial management staff's work and responsibilities fallen on specific sectors and individuals.

\subsection{To standardize the procedures of the financial work}

The procedures of the financial work have to be standardized in order to achieve the enterprise's refined financial management. The enterprise's management personnel must refine the procedures of the financial management work of each sector which need to be fully grasped and controlled in order to realize the financial management targets. Enterprises can formulate relevant regulations and standards to strengthen supervision and make up for the deficiency of the financial management work which can guarantee the normal operation of the enterprise's economic activities. Thus, the enterprise must refine its procedures of the financial management work in order to achieve the refined financial management. The financial procedures can be optimized to improve the efficiency and quality of financial management.

\subsection{To actively change the management concept}

Enterprises must actively change their management concepts, establish the concept of refined management, and put forward effective measures in the daily financial management work in order to effectively implement the refined financial management. At present, some enterprises have some misunderstanding about the refined financial management. They regard the financial work as the accounting work, which causes their functions and roles to be not fully played and hinders their development. Therefore, enterprises must change their dated management mode, and make careful analysis of the refined financial management. They should realize the importance of the refined financial management for their development, and change the focus in their operating and management to improve the efficiency and quality of their financial work.

\subsection{To promote the construction of informatization of financial management}

The realization of the refined financial management must promote the construction of informatization of financial management and strengthen the control of the financial information system. It can be achieved by the following steps: firstly, the enterprise should strengthen the internal auditing control and increase the reliability and authenticity of financial information; secondly, the enterprise should improve the security of information system and restrict the behavior of the personnel who have nothing to do with informatizaion; thirdly, the enterprise should increase the control of financial organizations and strengthen the construction of management system. It should also specify job 
responsibilities of the financial management staff and improve its internal organization; fourthly, the enterprise should standardize the procedures of its financial management work; fifthly, the enterprise should strengthen its control over financial accounting to carry out its financial activities perfectly.

\section{Conclusion}

In summary, it is necessary for the enterprise to realize its refined financial management which is good for carrying out its financial work. At present, there are many problems in the financial management of modern enterprises, which lead to many financial risks in the enterprise's operating and management. So to further study the refined financial management and put forward effective methods will improve the financial management and promote the sustainable development of enterprises.

\section{References}

1. Cao Jian. Exploration of the enterprise's refined management. J. Technology wind, 2011, (24): 265266.

2. Zhang Jingjun. Research on the enterprise's refined management. J. Management and Research on Scientific \& Technological Achievements, 2010, (8): 100-101.

3. Zhang Baoding. The refined management of enterprises and the refinement of financial management. J. Contemporary Economic, 2008, (22): 59-60. 